\title{
A PUBLICIZAÇÃO DA PRODUÇÃO DO ESPAÇO URBANO NO DIREITO URBANÍSTICO BRASILEIRO
}

\section{MAKING THE PRODUCTION OF URBAN SPACE A PUBLIC FUNCTION IN BRAZILIAN URBAN LAW}

\section{Cesar Tavares ${ }^{1}$}

\section{Resumo}

Este artigo defende a tese de que a produção do espaço urbano, nos termos da Constituição Federal de 1988, é um serviço público de competência municipal e não uma atividade econômica livre à iniciativa privada e regulada pelo poder público. Partindo de uma crítica às leituras que tradicionalmente são feitas da Lei de Parcelamento de Solo e do Estatuto da Cidade, o texto descreve os princípios fundamentais do Direito Urbanístico Espanhol, como paradigmas de comparação, para buscar os fundamentos que permitem afirmar a tese proposta em face do Direito Urbanístico Brasileiro. Por fim, o Reordenamento Urbanístico Integrado, tal como previsto no Plano Diretor de São Paulo, é estudado e destacado como um caso de publicização da produção do espaço urbano, demonstrando que os municípios têm respaldo na Ordem Constitucional Brasileira para criar instrumentos de política urbana que Ihes possibilitem apropriar a produção do espaço urbano como um serviço público.

Palavras chave: Lei de Parcelamento de Solo; Reordenamento Urbanístico Integrado; produção do espaço urbano; intervenção estatal na economia; serviço público.

\section{Abstract}

This article argues that the urban space production, in accordance with the Federal Constitution of 1988, is a public service of municipal competence and not a private economic activity regulated by the Government. Starting from a critical point of view over traditional analysis made about Soil Installment Law and Brazilian Cities Law, the text describes the fundamental

\footnotetext{
${ }^{1}$ Bacharel em Direito pela UNESP, campus de Franca; Mestre em Direito do Estado pela Faculdade de Direito da Universidade de Coimbra, Portugal; Doutor em Direito Ambiental Internacional pela Universidade Católica de Santos; Chefe Procuradoria Jurídica da Secretaria de Negócios Juridicos de Salto de Pirapora/SP; Professor Substituto da Ufscar, Campus Sorocaba (2011-2013); Professor da Faculdade de Direito de Sorocaba (2004-2010). E-mail: cetav73@gmail.com
} 
principles of Spanish Urban Law, as a paradigm of comparison, to pick up the Brazilian urban law fundamentals that allow affirming the thesis proposed in this work. Finally, the "Integrated Urban Redevelopment", as regulated in the São Paulo Master Plan, is studied as a case of urban space production by the local government, demonstrating that the municipalities have supported by the Brazilian Constitutional Order to create urban policy instruments that allow them to take over the production of urban space as a public service.

Keywords: Soil Installment Law; Integrated Urban Redevelopment; urban space production; state intervention in the economy; public service.

\section{INTRODUÇÃO}

Em que pese a notável evolução legislativa ocorrida no Direito Urbanístico Brasileiro após a Constituição de 1988, estabelecendo-se a função social da propriedade como fundamento para implementação de uma política urbana efetiva, a hipótese que se pretende colocar neste texto é a de que o Direito Urbanístico no Brasil ainda é influenciado por uma concepção liberal de desenvolvimento urbano. Segundo uma perspectiva comparada com o direito espanhol, é possível observar que a legislação urbanística infraconstitucional ainda reserva ao Estado uma limitada função indutora, apesar de alguns avanços recentes na legislação e da uníssona aceitação do princípio da função social da propriedade como fundamento do direito urbanístico.

A Lei de Parcelamento do Solo foi a primeira legislação propriamente urbanística no direito brasileiro, gerando uma revolução na regulação da matéria, ao condicionar os projetos de parcelamento de solo a diretrizes gerais da lei e a normas específicas fixadas pelos municípios. O avanço trazido pela lei de parcelamento de solo consistiu em superar a regulação anterior, de natureza estritamente civilista, a qual se detinha somente nos aspectos contratuais relativos à aquisição de lotes urbanos.

O Estatuto da Cidade, por sua vez, regulamentou o Capítulo da Política Urbana na Constituição, dando eficácia plena aos dispositivos constitucionais relacionados à matéria. Trata-se de lei geral em matéria de direito urbanístico que criou um horizonte de atuação bastante amplo para os municípios, no exercício de sua competência urbanística. No entanto, em aparente contrariedade aos objetivos fundamentais da lei, os instrumentos de política urbana especificamente detalhados no Estatuto da Cidade são destacados como instrumentos 
de regulação de mercado, um vez que, em regra, visam induzir os particulares a usar a propriedade nos termos das diretrizes estabelecidas no Plano Diretor.

Apesar da relevância e atualidade dessas leis, que instituíram importantes instrumentos de intervenção sobre a propriedade e permitiram dar consistência ao Direito Urbanístico Brasileiro, este estudo pretende demonstrar que essas leis são ordinariamente lidas segunda uma perspectiva liberal, a qual limita-se a reservar uma função reguladora para o poder público.

Nesse sentido, a produção do espaço urbano seria uma função do mercado e o Direito Urbanístico o seu limite regulatório. A argumentação que aqui se pretende estabelecer, portanto, defenderá a tese de que a Constituição Federal define a função de produção do espaço urbano como uma função pública, devendo-se enquadrar a legislação infraconstitucional conforme essa orientação constitucional.

Para atingir esse objetivo, o raciocínio do presente trabalho se desenvolverá em duas etapas complementares: a primeira consistirá em evidenciar que a função urbanizadora, ou seja, a função de produzir o espaço urbano, continua sendo majoritariamente enquadrada como uma decorrência do exercício do direito de propriedade (item 1); a segunda etapa objetivará construir um referencial teórico que sustente a publicização da função de produção do espaço urbano (itens 2 e 3). Na segunda etapa se realizará uma breve síntese dos princípios fundamentais do direito urbanístico espanhol, focando-se especialmente o instituto da reparcelación del suelo urbano (item 2) e extraindo-se daí os elementos teórico-comparativos necessários para: i) propor uma releitura do Estatuto da Cidade e da Lei de Parcelamento de Solo, segundo uma perspectiva de publicização da função urbanizadora (item 3); ii) compreender o instituto do Reordenamento Urbanístico Integrado do Plano Diretor Estratégico de São Paulo (item 3) como instrumento de publicização da produção do espaço urbano.

Do ponto de vista metodológico, a estratégia adotada consistiu em abordar o direito urbanístico espanhol, em especial, o instituto da reparcelación del suelo urbano, para se identificar que elementos do direito espanhol definem a produção do espaço urbano como uma função pública. A seguir, passou-se à identificação de elementos no direito brasileiro que pudessem funcionar no mesmo sentido de apropriação pública da função urbanizadora. A vantagem da metodologia proposta neste trabalho está em ganhar uma visão mais abrangente que possibilita enxergar os instrumentos urbanísticos de uma forma inovadora e propor a sua releitura de um modo que supere as visões liberalizantes que colocam o direito de propriedade principal vetor da produção do espaço urbano. 
ESTATUTO DA CIDADE E LEI DE PARCELAMENTO DO SOLO URBANO, AINDA UMA PARADIGMA LIBERAL?

Com relação à legislação urbanística brasileira, Victor Carvalho Pinto (2010, p. 01) destaca que, "em comparação com outros países, a legislação brasileira ainda se apresenta muito assistemática e incompleta, o que tem impedido a institucionalização do planejamento urbano."

De fato, a legislação federal diretamente relacionada ao Direito Urbanístico (PINTO 2010, p. 02) abrange apenas quatro leis federais e uma medida provisória, todas editadas em momentos diferentes, para atingir objetivos diversos, conforme se observa neste breve resumo: a Lei no 6766/1979 regula o parcelamento do solo urbano e foi editada para exigir um mínimo de infraestrutura urbana nos projetos de urbanização, os quais eram tradicionalmente regulados por normas de natureza cível, preocupadas apenas com a questão contratual da venda dos lotes; a Lei no 10.257/2001, o Estatuto da Cidade, foi editada mais de dez anos depois da Constituição e resultou de histórica demanda da sociedade para regulamentar os artigos 182 e 183 da Constituição Federal e efetivar o direito à cidade; a Medida Provisória no 2220/2001, que dispõe sobre a concessão de uso especial para fins de moradia em áreas públicas, foi editada para suprir a lacuna criada por veto presidencial a dispositivos do Estatuto da Cidade; a Lei no 11.977/2009, dispôs sobre o Programa Minha Casa, Minha Vida e a sobre a regularização fundiária de assentamentos localizados em zonas urbanas, representando enorme esforço para restabelecer uma política de habitação e combater a informalidade no espaço urbano; e, finalmente, a Lei no 13.465/2017, que dispôs sobre a regularização fundiária, revogando parcialmente a Lei 11.977/2009 e prometeu dar uma regulação mais ampla do que a norma anterior em matéria de regularização fundiária, trazendo grande polêmica sobre o assunto ${ }^{2}$.

A acumulação de texto legais com objetivos diversos, sem uma preocupação em sistematizar a matéria urbanística, coloca a questão sobre a quem pertence a titularidade da função de produzir o espaço urbano, conforme se observará nas próximas seções.

\footnotetext{
${ }^{2}$ A polêmica consiste basicamente em confundir regularização fundiária com legalização da grilagem de terras, conforme se observa do texto de Brum (2017).
} 


\section{O parcelamento do solo urbano como prerrogativa do direito de propriedade}

A Lei de Parcelamento de Solo regula o procedimento para converter glebas indivisas em lotes urbanos dotados de infraestrutura e equipamentos públicos. Trata-se do primeiro marco legal de regulação urbanística no direito brasileiro, convertendo-se no principal instrumento de regulação da produção do espaço urbano, uma vez que as novas áreas regularmente urbanizadas são obtidas através dos processos de parcelamento de solo.

Sobre a articulação entre a Lei de Parcelamento de Solo e as leis urbanísticas municiais no ordenamento das cidades, Rolnik e Klink (2011, p. 15) concluem que se trata de verdadeira privatização da produção do espaço urbano:

Paralelamente, o mesmo Estado regulou a produção e a expansão das cidades, por meio de leis de parcelamento, zoneamentos e planos urbanísticos, delegando ao loteador privado a missão de produzir terra urbanizada, com infraestrutura e espaços públicos para a expansão da cidade. De acordo com este modelo, o mercado formal de urbanização produz, privadamente, "cidade".

É importante discutir o significado da Lei de Parcelamento de Solo, e do marco legal nela inaugurado, em face das finalidades consagradas pelo Capítulo da Política Urbana na Constituição de 1988. O problema está em que a Lei no 6766/1979 não define expressamente o parcelamento de solo como uma função pública do município, em que pese estabelecer que cabe ao município o licenciamento e o controle sobre os processos de parcelamento de solo. Essa disciplina legal configura uma aparente incompatibilidade em face do texto constitucional, uma vez que, dada a relevância do parcelamento de solo para a produção do espaço urbano, seria natural pensar que se trata de um instrumento essencial à política de desenvolvimento urbano.

Para haver maior coerência com o texto da Constituição Federal, o parcelamento de solo deveria ser expressamente enquadrado como uma competência reservada ao município, tendo em vista que o município detém não somente a competência normativa de planejar o desenvolvimento urbano, nos termos do caput do art. 182, como também recebeu a competência material de executar o adequado ordenamento do território, nos termos do inciso VIII do artigo 30, ambos da Constituição Federal de 1988.

No entanto, não é esse o entendimento que ordinariamente se dá à Lei de Parcelamento de Solo. Do modo como se encontra regulada pela Lei 6766/1979, a atividade de 
parcelamento de solo é considerada uma prerrogativa do proprietário da gleba a ser parcelada, como natural manifestação do direito de propriedade 3 .

No sentido desse entendimento, observe-se o artigo 6으 da Lei no 6766/1979, que define as posições do Poder Público e dos particulares no processo de parcelamento de solo nos seguintes termos:

Antes da elaboração do projeto de loteamento, o interessado deverá solicitar à Prefeitura Municipal, ou ao Distrito Federal quando for o caso, que defina as diretrizes para o uso do solo, traçado dos lotes, do sistema viário, dos espaços livres e das áreas reservadas para equipamento urbano e comunitário, apresentando, para este fim, requerimento e planta do imóvel (...)" (destaques nossos)

Assim, sem maiores questionamentos em face da Constituição Federal, interpreta-se que, nos termos do artigo 60, o proprietário do solo seria o interessado, titular do direito de promover o parcelamento de solo, restando ao município a competência para, no exercício de seu poder de regulação, emitir as diretrizes limitadoras do direito do particular em nome do interesse público. A função do município, por conseguinte, seria meramente indutora da atividade econômica de parcelamento do solo urbano.

No uso de seu direito de propriedade, em que pesem as limitações estabelecidas pelo poder público, o particular-proprietário acaba figurando como o agente privilegiado da produção do espaço urbano. Ao município, titular da política de desenvolvimento urbano e detentor da competência para definir a função social da propriedade, restaria a função de controle externo sobre os processos de parcelamento, a fim de impor a obediência à legislação municipal, em especial, ao Plano Diretor.

Segundo esse enquadramento da Lei 6766/1979 na ordem jurídica, a propriedade privada estaria na origem dos processos de parcelamento do solo urbano, destacando-se a figura do titular da propriedade como o agente primaz da produção do espaço urbano. Tal concepção sobre a Lei Parcelamento de Solo, no entanto, conflita com a concepção de função social de propriedade, que coloca o uso econômico da propriedade privada como uma função do planejamento público desenvolvido pelo município. Também conflita com a competência municipal de promover o adequado ordenamento territorial conforme o art. 30, inciso VIII, da

\footnotetext{
${ }^{3}$ Ver Araújo e Lorenzetti (2008, p. 23), taxativos no sentido de que "apenas o proprietário da gleba pode promover o loteamento ou o desmembramento. A doutrina chega a mencionar o parcelamento promovido por compromissário comprador, com anuência expressa do proprietário e cláusula que obrigue o proprietário a, uma vez rescindido o contrato de compra e venda, assumir as obrigações do parcelador."
} 
Constituição Federal, relegando o município à condição de agente meramente regulador da atuação dos particulares proprietários e incorporadores imobiliários.

\section{O Estatuto da Cidade como norma reguladora da produção do solo urbano pelo mercado imobiliário}

Também o Estatuto da Cidade, Lei no 10.257/2001, pode ser interpretado de maneira a circunscrever as funções do município, no desenvolvimento de sua política urbana, a controles regulatórios limitadores da atividade econômica dos particulares no âmbito do "mercado imobiliário".

No caput do artigo 182 da Constituição de 1988, o Estatuto da Cidade é definido como a lei de diretrizes gerais que possibilita ao município implementar a sua política de desenvolvimento urbano. Nesse sentido, é importante refletir sobre a natureza das funções que o Estatuto da Cidade reserva para os municípios. A finalidade sempre será a de condicionar a propriedade privada ao atendimento de sua função social, porém, há divergências sobre o modo como essa finalidade pode ser atingida, gerando assim, diferentes concepções sobre a natureza e os limites dos poderes reservados aos municípios.

Victor Carvalho Pinto (2011), relacionando análise econômica e política de desenvolvimento urbano, entende que os instrumentos de política urbana são mecanismos de superação das falhas do mercado imobiliário. Nesse sentido, destaca que o mercado imobiliário, segundo sua lógica natural de maximização do lucro, não se interessa por prover os bens coletivos necessários ao desenvolvimento urbano, de modo que caberia ao poder público, através do plano diretor e dos instrumentos previstos nos Estatuto da Cidade, limitar o exercício do direito de propriedade, para induzir a sua utilização na obtenção de bens coletivos (preservação de áreas ambientais, reserva de áreas institucionais e de lazer, provisão de infraestrutura de serviços públicos, etc.) e no combate a práticas abusivas, como a especulação imobiliária.

A explicação da tese adotada por Victor Carvalho Pinto pode ser buscada na classificação das categorias fundamentais do Direito Econômico, que dividem a atuação do Estado sobre a economia em duas modalidades: 1) a intervenção estatal em sentido estrito, compreendida como o desempenho material e direto de atividades econômicas pelo Estado, que assim atuaria diretamente como um agente econômico, ao lado dos particulares; 2) a regulação, compreendida como a atividade estatal de emissão de normas, fiscalização de seu 
cumprimento e sancionamento (positivo ou negativo) pelo seu descumprimento, para condicionar a atuação dos particulares (por meio da repressão ou do incentivo), vinculando-os ao atingimento de finalidades públicas maiores ${ }^{4}$.

Com base nessas duas modalidades básicas de intervenção estatal na economia, é possível classificar as atividades da Administração Pública da seguinte maneira: a) grupo das atividades administrativas de exploração direta da atividade econômica e de prestação de serviços públicos, que são manifestações da intervenção estatal em sentido estrito, destacandose que, no primeiro caso, a Administração atua em regime de direito privado, nos termos do artigo 173 da CF/88 e, no segundo caso, a Administração Pública absorve atividades econômicas relevantes para a Sociedade, convertendo-as em funções públicas, desempenhadas em regime de direito público, nos termos do artigo 175 da CF/88; b) grupo das atividades regulatórias da Administração Pública, as quais são tradicionalmente conhecidas como poder de polícia e fomento da Administração Pública, lembrando-se que, no primeiro caso, a atuação estatal se dá mediante o uso de sanções coercitivas e, no segundo caso, pela aplicação de sanções premiais.

Segundo a orientação liberal que, desde a década de 1970, vem preconizando um modelo de Estado não intervencionista, a atuação estatal na ordem econômica deve restringirse apenas ao desempenho de atividades regulatórias, reduzindo-se as atividades de intervenção direta na economia, uma vez que consideradas disfuncionais para a livre iniciativa e violadoras de um suposto princípio da subsidiariedade, o qual, diga-se de passagem, não foi previsto na Ordem Constitucional de 1988, conforme destaca Bercovici (2015).

Nesse sentido, promove-se uma leitura enviesada da ordem econômica constitucionalmente estabelecida, passando-se a conceber que a intervenção econômica estatal seria estritamente regulatória. Segundo tal perspectiva, os resultados decorrentes das atividades de intervenção direta poderiam ser obtidos com maior eficiência mediante o reforço das atividades regulatórias e a entrega ao setor privado das atividades econômicas tradicionalmente desenvolvidas pelo Estado. Assim, a atuação estatal direta na economia seria meramente residual e orientada para reforçar a regulação econômica.

Moreira (2007, p. 10) explica que na origem dessa tendência estaria a profusão do chamado "american-style regulation":

Especificamente no que diz respeito à regulação econômica, Giandomenico Majone vale-se reiteradamente da expressão "Americanstyle regulation" para se referir à forma de intervenção estatal que acredita no funcionamento perfeito do mercado em circunstâncias

\footnotetext{
${ }^{4}$ Conforme Moreira (2007, p. 03)
} 
normais e que, por isso, deixa a propriedade das empresas em mãos de pessoas privadas. A intervenção dar-se-ia puramente através de normas (em menor número possível) e o Estado apenas sanaria as falhas de mercado (ao que se infere, numa atuação pró-mercado).

Mas o essencial disso está em seu significado macroeconômico (e mesmo "macrojurídico"). Não significa apenas uma opção catalográfica, oriunda de conceitos normativos neutros. A defesa de uma American-style regulation não implica somente um enfoque privilegiado da atividade normativa. Mais do que isso, traz consigo uma específica concepção de todo o relacionamento do Estado com a economia. Não envolve apenas a atenuação da intervenção direta e o favorecimento à intervenção regulatória, numa singela alteração dos modos de intervir, mas sim uma diferente concepção estrutural da própria economia, do papel do Estado e dos agentes econômicos. Altera-se toda a rationale do sistema.

Não é escopo deste trabalho o aprofundamento das questões teóricas relacionadas ao tamanho do Estado e ao chamado "direito regulatório", importando destacar que muitas das leituras sobre o Estatuto da Cidade são alinhadas a uma perspectiva liberal, por mais que não se queira admitir esse fato. Com isso, prevalece uma concepção reducionista quanto à natureza pública da função de produção do espaço urbano.

Nesse sentido, é possível afirmar que a doutrina dominante sobre o Estatuto da Cidade concebe a existência de prerrogativas importantes para o poder público nos processos urbanos, prerrogativas que podem condicionar o direito de propriedade nos termos do Plano Diretor, mas que, no entanto, não são capazes de reverter a precedência do direito de propriedade na produção e reprodução do espaço urbano.

Trata-se de perspectiva teórica que reproduz a mesma sistemática já mencionada a respeito do parcelamento do solo urbano, uma vez que descreve instrumentos interventivos de política urbana, os quais visam combater a especulação imobiliária, induzir o uso da propriedade num sentido socialmente justo, limitar o uso abusivo do direito de propriedade, mas ainda reconhecendo o mercado imobiliário e a propriedade privada como os elementos centrais dos processos urbanos.

De fato, institutos como a outorga onerosa do direito de construir e da alteração de uso (artigos 28 a 31 do Estatuto da Cidade) são importantes mecanismos de "captura de mais valias urbanas $^{\prime 5}$ para o poder público e permitem um importante controle público sobre aspectos (direito de construir e a definição das finalidades no uso da propriedade) que antes eram uma decorrência natural do direito subjetivo de propriedade. Porém, esses institutos não alteram a precedência da decisão do particular-proprietário (ou do incorporador imobiliário) sobre o uso

\footnotetext{
5 Nesse sentido, para um aprofundamento sobre o tema, bem como sobre o uso dos conceitos relacionados, ver Santoro (2004).
} 
da propriedade, em que pese representarem importante mecanismo para obter recursos públicos com a regulação do interesse econômico do particular.

É interessante destacar que os mecanismos de outorga de direitos para a apropriação pública das mais valias urbanas podem resultar em redução do valor do solo e diminuir a participação do proprietário na riqueza gerada pela produção do espaço, contribuindo, inclusive para alimentar a capacidade púbica de prover habitação social e infraestrutura. No entanto, esses mecanismos não são suficientes determinar os processos de mercado e modificar o espaço urbano em conformidade com os planos. Os instrumentos de outorga para apropriação das mais valias urbanas não estabelecem um controle todo-compreensivo sobre a integralidade da relação custo-benefício dos processos urbanos, de modo que não reservam ao Poder Público a capacidade de arbitrar a distribuição dos lucros ou interferir na eficiência econômica da produção do espaço.

O direito de superfície (artigos 21 a 24 do Estatuto da Cidade) "permite que o proprietário conceda a outra pessoa o direito de utilizar o solo, o subsolo ou o espaço aéreo de seu terreno" (MATTOS 2003, p. 78) e representa uma importante ferramenta à disposição do poder público para induzir o comportamento de proprietários na preservação de imóveis com valor histórico ou ambiental. No entanto, não se trata de um mecanismo capaz de trazer para o poder público a precedência sobre os processos urbanos, podendo até mesmo levar ao locupletamento do particular em prejuízo da captação de recursos públicos, se utilizado de forma abusiva e em desrespeito às suas finalidades fundamentais. É o que ocorre quando os planos diretores liberam indiscriminadamente a possibilidade de transferência o direito de construir como um mecanismo de compensação pela imposição de potencial construtivo único no plano diretor.

As operações urbanas consorciadas (artigos 32 a 34 do Estatuto da Cidade) permitem flexibilizações nos parâmetros urbanísticos previstos no Plano Diretor, com o objetivo de induzir investimentos privados na requalificação de espaços e ainda extrair recursos para que o poder público possa investir em infraestrutura urbana na área de intervenção. Como se observa, também neste caso, existe importante intervenção pública, mas que não afeta a precedência da decisão primária a ser tomada pelo particular-proprietário quanto ao uso da propriedade. Tratase inclusive de um instrumento que pode ser objeto de crítica, no sentido de que os recursos resultantes da flexibilização dos padrões urbanísticos são usados em infraestrutura na área da 
operação consorciada, em prejuízo de outras áreas urbanas eventualmente mais críticas, do ponto de vista da necessidade de investimentos públicos ${ }^{6}$.

O direito de preempção (artigos 25 a 27 do Estatuto da Cidade) estabelece que "o Município tem a preferência para a compra de imóvel urbano, objeto de alienação onerosa entre particulares, desde que situado em área previamente delimitada por lei municipal, assegurado o valor de mercado." (MATTOS 2003, p. 79) Trata-se de mecanismo de intervenção no mercado de solo urbano, em que o município pode interferir nas relações contratuais privadas, para induzi-las em certo sentido favorável ao interesse público, evidenciando com maior clareza o fato de que o Estatuto da Cidade caracteriza os planos diretores como ferramentas de indução dos processos urbanos, sem no entanto alterar a precedência do mercado sobre esses processos.

Essa orientação teórica é bastante perceptível no ponto de vista de Fernandes (2006, p. 15), que destaca os avanços trazidos pelo Estatuto da Cidade nos seguintes termos ${ }^{7}$ :

O Estatuto da Cidade promoveu uma mudança estrutural no planejamento urbano brasileiro, que passa a ser não apenas o planejamento regulatório tradicional, mas também um planejamento indutor de processos territoriais e urbanísticos que tenham um impacto direto na dinâmica dos preços do mercado imobiliário, processo esse que pode levar à ocupação de vazios urbanos e à distribuição mais justa dos ônus e benefícios da urbanização.

Outros autores de Direito do Urbanismo seguem a mesma orientação, conforme se observa de suas concepções de Plano Diretor, nos seguintes excertos de suas obras:

É instrumento básico de atuação. Por meio dele, Administração Pública e sociedade terão base para agir segundo suas próprias finalidades. Traz segurança para a iniciativa privada e responsabilidade para o Poder Público. Deve ser precedido de uma dinâmica de planejamento que, pelo levantamento de dados e índices, verificará as carências e necessidades, apontando soluções. Este resultado será traduzido em um documento que será o plano. (DI SARNO 2004, p. 62)

(...) cabem às normas do plano diretor estabelecer os limites, as faculdades, as obrigações e as atividades que devem ser cumpridas pelos particulares referentes ao direito de propriedade urbana. Ao plano diretor é incumbida a tarefa de estabelecer como normas imperativas aos particulares e agentes privados as metas e diretrizes da política urbana, os critérios para verificar se a propriedade atende sua função social, as normas condicionadoras do exercício desse direito. (SAULE JUNIOR 2002, p. 258)

\footnotetext{
${ }^{6}$ Nesse sentido, ver MONTANDON e SOUZA (2007).

${ }^{7}$ Ver também Pinto (2011, p. 103) e Mattos (2003, p. 65).
} 
Deve-se destacar também o fato de que parte da doutrina em Direito do Urbanismo atribui os problemas urbanos à alegação de falta ou deficiência de planejamento que acompanhou o intenso processo de urbanização ocorrido ao longo do século XX.

Para Di Sarno (2004, p. 64-65),

A ausência de plano urbanístico não impede que o Poder Público elabore ações pontuais, porém, a localidade desprovida de plano será refém do imediatismo, do improviso, da insegurança que a falta de planejamento traz. A consequência é visível nas cidades brasileiras: são desordenadas, caóticas, desiguais e injustas. O custo social é profundo.

Carmona (2015, p. 158), ao comentar os instrumentos de política urbana previstos no artigo 4을 do Estatuto da Cidade, esclarece:

Não é mera coincidência que o primeiro conjunto de instrumentos previstos tenha sido o planejamento (incisos I a III), que, em matéria urbana, configura-se como verdadeiro pressuposto da ordem urbanística e, como se sabe, sua total ausência - infeliz tradição no nosso país gerou o crescimento urbano desordenado.

No entanto, no Brasil, a atividade de planejamento urbano é antiga, tendo nascido já em 1875. Trata-se de atividade que já passou por diversas fases, resultando numa produção extensa e variada de planos, que foram mais efetivos no período inicial, mas que, depois, passaram a se caracterizar como discursos ideológicos voltados a legitimar as decisões que efetivamente determinam o desenvolvimento urbano. Dessa forma, em que pese a grande proliferação de trabalhos e o gasto de recursos, a produção de planos de desenvolvimento urbano no Brasil não representou uma atividade que efetivamente determinasse o desenvolvimento das cidades brasileiras, exceto no período inicial, em que os planos eram voltados para a promoção de obras de melhoria e de embelezamento das cidades. (VILLAÇA 2010, p. 193-194)

Apesar desse histórico de grande valorização da atividade planejadora, as cidades brasileiras continuam a padecer de problemas básicos relacionados a temas como habitação, mobilidade, segregação social e meio ambiente. Nesse sentido, é possível afirmar que os problemas urbanos brasileiros não estão relacionados à falta de planejamento, mas à prevalência dos interesses de proprietários, empreendedores, especuladores, enfim de toda sorte de integrantes de uma elite econômica que domina os processos de produção do espaço urbano, respaldando-se no direito de propriedade.

Flavio Villaça (2010, p. 183) desenvolveu uma tese bastante interessante sobre a função do planejamento urbano no Brasil, destacando que toda a produção de planos urbanísticos nas cidades brasileiros ao longo do Século XX não passou de um discurso ideológico para esconder 
as políticas de desenvolvimento efetivamente adotadas nas cidades brasileiras. Conforme exposto por Villaça, as políticas urbanas que efetivamente estruturaram as cidades brasileiras foram voltadas para atender aos interesses das elites urbanas, que nunca tiveram propostas para resolver problemas importantes como habitação, saneamento, transportes e meio ambiente, nem se importaram em fazer com que a prática do planejamento urbano fosse efetivamente estruturante das cidades brasileiras ${ }^{8}$.

O direito de propriedade, portanto, nunca deixou de ser o elemento condutor do desenvolvimento urbano, de modo que as funções públicas de controle sobre o direito de propriedade nunca deixaram de ter um conteúdo liberal de limitação externa contra o uso abusivo do direito de propriedade. Mesmo no momento atual, em que se festeja a edição dos chamados instrumento de política urbana, conforme detalhados acima, é importante ressaltar que tais instrumentos não ultrapassam a lógica de limitação externa do direito de propriedade, ainda que em nome de novos valores, como o combate à especulação imobiliária, a apropriação das mais valias urbanas ou a justa distribuição dos ônus e benefícios do processo de urbanização. Invariavelmente, a propriedade privada continua a ser a matriz do processo de produção e reprodução do espaço urbano.

Nos momentos em que eventualmente houve qualquer tipo de ameaça a essa precedência do direito do propriedade, avançando-se no sentido de uma concepção pública de desenvolvimento urbano, o progresso sempre foi coartado pela imposição de tendências conservadoras, conforme relata Victor Carvalho Pinto (2012, p. 127), a respeito da rejeição do projeto de lei do Plano Diretor de São Paulo pela Câmara Municipal em 1991. O problema estava em que a proposta do plano diretor de São Paulo de 1991 pretendia superar a concepção de plano diretor como projeto de cidade futura, para substitui-lo por um conjunto de regras de gestão para induzir o desenvolvimento da cidade no presente. Ainda que a mudança proposta fosse tímida, a simples ameaça de uma interferência mais efetiva sobre o

\footnotetext{
${ }^{8} \mathrm{O}$ autor descreve sua reflexões nos seguintes termos:

Desde a década de 1930, vem-se desenvolvendo no Brasil uma visão do mundo urbano segundo a qual os problemas que crescentemente se manifestam são causados pelo seu crescimento caótico - sem planejamento -, e que um planejamento "integrado" ou "de conjunto", segundo técnicas e métodos bem definidos, seria indispensável para solucioná-los. Essa é a essência da ideologia do planejamento que ainda perdura. Há décadas nossas classes dominantes vem desenvolvendo interpretações sobre as origens dos problemas sociais que se manifestam agudamente em nossas cidades - especialmente os de habitação, transportes, saneamento e meio ambiente -, bem como sobre o papel do planejamento urbano na solução desses problemas. Tais ideias visam ocultar as verdadeiras origens daqueles problemas, assim como o fracasso daquelas classes e do Estado em resolvê-los. Com isso a dominação é facilitada. (VILLAÇA 2010, p. 183)
} 
direito de propriedade foi suficiente para causar a rejeição do projeto de lei na Câmara Municipal.

Referindo-se a esse momento e aos movimentos sociais de luta pela reforma urbana, Villaça (2010, p. 239) destaca:

É muito significativo que tenham sido exatamente aspectos urbanísticos referentes ao uso e ocupação do solo - os que mais geraram polêmicas, mobilizaram as forças do atraso, impediram a aprovação de vários planos diretores ou esterilizaram a ação dos que foram aprovados. Isso revela que, finalmente, veio à luz aquele aspecto que vinha sendo ocultado pela ideologia do plano diretor: os interesses vinculados ao espaço urbano.

Nesse passo, portanto, a tarefa a ser desenvolvida nos próximos itens será compreender de que modo se poderia estabelecer um regime urbanístico sobre a propriedade privada que fosse além da regulação indutora do direito de propriedade. Ou seja, um regime urbanístico que concebesse a política de desenvolvimento urbano como uma função pública (e não como mecanismo de superação das falhas de mercado) e que de fato realizasse a função social da propriedade.

\section{A reparcelación del suelo do Direito Urbanístico Espanhol}

Na doutrina espanhola, o Direito do Urbanismo é definido como a disciplina jurídica que se preocupa em regular o processo de construção das cidades (TIMÓN 2013, p. 11), dividindose em três âmbitos fundamentais:

1) Planejamento urbano, pelo qual se definem as partes do território que passarão a ser urbanas e que tipo de atividades se vão desenvolver nessas novas áreas urbanizadas (áreas urbanas), deixando-se muito claros os limites das áreas que se pretende proteger do processo de urbanização (áreas não urbanizáveis), bem como daquelas áreas que se pretende sejam estrategicamente reservadas para um futuro processo urbanizador (áreas urbanizáveis).

Nas palavras de Timón (2013, p. 11):

Se trata, utilizando uma descrição gráfica, de pintar por onde vai crescer a cidade no solo que não está urbanizado e que coisas serão desenvolvidas nos próximo anos no solo urbano, já urbanizado, protegendo assim, como solo não urbanizável a parte do território municipal que, por diversas razões, não se incorporará de imediato ao processo urbanizador.

2) Gestão urbanística, definida como o conjunto de atividades que efetivamente executam os planos, transformando o território do município em áreas urbanizadas; é o processo de urbanização propriamente dito e que deve estar conforme o que determina o plano de desenvolvimento urbano; 
3) Disciplina urbanística, que trata da submissão de sujeitos públicos e privados a poderes especiais de autoridade pública que verificam se a atividade urbanizadora efetivamente desenvolvida corresponde com o planejamento previamente concebido.

Mediante a articulação das funções públicas relacionadas a cada um desses três âmbitos, o Direito do Urbanismo condiciona o direito de propriedade, não pela simples limitação externa ou pela indução dos processos de mercado, mas convertendo a situação jurídica do proprietário de terra em uma situação estatutária, pela qual o proprietário possui somente os direitos e deveres estabelecidos na ordem jurídica, assegurando-se que o desenvolvimento urbano não seja uma função da vontade pessoal do detentor da propriedade.

No âmbito da função de planejamento, a propriedade urbana submete-se a diferentes regimes jurídicos, conforme esteja situada em área urbana, urbanizável ou não urbanizável, traduzindo-se assim a sua situação estatutária. As áreas classificadas como urbanas estão prontas para receber projetos de urbanização, no modo e no tempo determinados pelo município, que deve editar o plano detalhado do projeto de urbanização a ser implementado. É importante destacar que esses planos de urbanização devem especificar o desenho das novas áreas urbanas, os equipamentos públicos e infraestruturas públicas que serão instalados, as construções a serem comercializadas e todo o cálculo dos custos e benefícios que serão gerados com a sua implementação.

A gestão urbanística, por sua vez, compreenderá os diferentes métodos disponibilizados ao município para executar os planos definidos na fase anterior. Independentemente do método de execução adotado, o problema fundamental a ser resolvido nesta fase será transformar a estrutura fundiária da área objeto da urbanização, bem como definir a distribuição dos custos e benefícios decorrentes da implantação do projeto.

A reparcelacion del suelo urbano, portanto, é o instrumento urbanístico que resolve as questões principais da gestão urbanística. Trata-se de ferramenta pela qual se promove o rearranjo fundiário ${ }^{9}$ de uma área delimitada. 0 objetivo é preparar a estrutura fundiária dessa área para receber um projeto de urbanização que deve ser executado sobre um conjunto desorganizado de glebas de diferentes proprietários. Dessa forma, as glebas desorganizadas serão transformadas em um novo espaço urbano, redesenhado e infraestruturado. Ou seja, projeta-se o redesenho de uma determinada área a partir de antigas propriedades, as quais serão substituídas por novas propriedades, sem que haja a necessidade de se promover a

\footnotetext{
${ }^{9}$ Nesse sentido: Pinto (2013, p. 07) e Souza (2009, p. 29).
} 
desapropriação dos antigos imóveis. Destaque-se que, para alguns proprietários a desapropriação pode ser necessária, quando o particular pretender obter indenização econômica, no lugar da relocalização de sua propriedade dentro do espaço previsto no projeto de urbanização (cf. RAMÓN 2013, p. 194).

A lógica desse instituto não é de difícil compreensão. O poder público destaca uma determinada área de intervenção e elabora o projeto de reparcelamento do solo ${ }^{10}$, acrescentando o cálculo do total de receita a ser gerada pelo potencial construtivo da área, mediante a aplicação dos índices urbanísticos previstos no plano diretor. Nesse cálculo também são inseridos os custos totais do projeto, incluindo-se as novas edificações, as infraestruturas e equipamentos públicos, bem como o custo total das antigas propriedades envolvidas no projeto. Ao final efetua-se a contabilidade geral do projeto, compensando as receitas previstas e os custos totais ${ }^{11}$.São incluindos os lucros das empresas responsáveis pela urbanização, quando se proceder através de concessão para a iniciativa privada. Na contabilidade geral do projeto de urbanização, parte dos novos imóveis projetados é destacada em pagamento pelos antigos imóveis utilizados, outra parte é direcionada para cobrir os custos das obras e das infraestruturas públicas, restando ainda um excedente de imóveis que é destinado ao poder público como forma de pagamento pela valorização imobiliária gerada pela execução do projeto e também para garantia de habitação de interesse social. Caso o projeto contemple obras e equipamentos públicos excepcionais, como, por exemplo, um hospital, uma linha de metrô, uma ponte e assim por diante, será necessário um aporte extra de recursos públicos.

As principais vantagens decorrentes da utilização desse instituto são as seguintes ${ }^{12}: 1$ ) permite a intervenção em extensas áreas urbanas, sem que as dimensões das propriedades privadas envolvidas constitua um fator limitador dos projetos a serem desenhados; 2) supera as dificuldades geradas por demorados e custosos processos de desapropriação; 3) impede que os particulares aproveitem-se do interesse público na requalificação do espaço urbano para promover uma sobrevalorização artificial das indenizações pelos seus imóveis; 4) previne a chamada "loteria do planejamento urbano" (TIMÓN 2013, p. 39), que consiste na ocorrência de injustiças geradas pela atividade de planejamento, em razão da aleatoriedade da

\footnotetext{
${ }^{10}$ Timón (2013, p. 39 seguintes)

${ }^{11}$ Conforme destaca Ramón (2013, p.194) o objeto da reparcelación não é o solo em si mesmo, mas sim a projeção econômica de seu aproveitamento nos termos do plano diretor, de modo que "(...) os proprietários se sub-rogam na titularidade de novas parcelas de solo (relocalização da propriedade), materializando assim seus direitos ao aproveitamento urbanístico (...)" (destaque nosso).

12 Souza (2009, p. 42-43); Pinto (2013, p. 07-16).
} 
supervalorização ou da superdepreciação de imóveis resultantes da localização dos equipamentos e infraestruturas públicos; 5) promove o cálculo exato dos custos e benefícios da atividade urbanizadora e projeto de forma equitativa a sua distribuição entre os interessados; 6 ) gera recursos (as mais valias urbanas) que podem ser canalizados para o poder público investir em melhorias socais, como moradias populares ou obras de infraestrutura excepcionais.

De outro lado, o reparcelamento de solo pressupõe um detalhado planejamento, que envolve não somente o plano diretor e seus índices urbanísticos gerais, mas também os planos de detalhe contemplando o desenho do espaço urbano, o cálculo de infraestruturas, custos e recursos a serem gerados, bem como parâmetros e modelos de edificações, a destinação de todos os espaços públicos e a reserva de unidades para habitação social. Na medida em que esse processo implica no uso de propriedades privadas, uma intensa participação dos sujeitos envolvidos é necessária, para além dos cidadãos em geral, que necessariamente deverão participar do processo para legitimar as drásticas intervenções públicas projetadas. O reparcelamento de solo, portanto, torna possível a apropriação pública do processo de produção do espaço urbano, materializando a concepção de função social da propriedade.

A experiência do Direito Urbanístico Espanhol evidencia dois pontos fundamentais: i) a construção do espaço urbano deve ser resultante de um processo público e coletivo de decisão e não um produto econômico decorrente do exercício do direito de propriedade; ii) os custos e benefícios econômicos gerados na produção do espaço urbano devem ser publicamente contabilizados, no formato de um verdadeiro serviço público, evitando-se que a função urbanizadora seja reduzida a uma simples renda pelo uso do solo em proveito exclusivo dos proprietários e de seus associados (construtoras, incorporadoras e financiadoras de "negócios imobiliários"13).

Os próximos itens deste trabalho, portanto, serão dedicados a demonstrar que o Direito Urbanístico Brasileiro possui institutos capazes de conduzir a produção do espaço urbano no sentido da realização desses dois pontos fundamentais. Além disso, também se evidenciará que a Lei de Parcelamento de Solo e o Estatuto da Cidade podem ser lidos de outra forma, mais

13 O termo foi usado entre aspas, uma vez que não se pode chamar "negócio imobiliário" empreendimentos pensados dentro dos limites de cada propriedade individualmente considerada e que priorizam a produção de edificações dissociadas de uma visão mais ampla de planejamento urbano e de cidade. A projeção de externalidades, a valorização ou desvalorização geradas, o custo da infraestrutura, o impacto sobre a sociedade ou sobre as redes consolidadas no espaço urbano, são fatores que não entram na contabilidade dos "negócios imobiliários" brasileiros, os quais são pensados sob a lógica de maximização e distribuição de lucros pelo uso da propriedade. 
coerente com o princípio da função social da propriedade, de modo que não se limitam instrumentos de regulação para corrigir falhas do mercado imobiliário.

\section{O Reordenamento Urbanístico Integrado do Plano Diretor de São Paulo, instrumento de publicização da produção do espaço pelo município}

O Município de São Paulo, através de seu Plano Diretor Estratégico (PDE), Lei Municipal no 16.050/2014, conforme $\S 20$ do artigo 134, previu o instituto do Reordenamento Urbanístico Integrado. Trata-se de instrumento que possibilita o rearranjo fundiário da área de intervenção, mediante a unificação dos registros imobiliários dos terrenos compreendidos na área afetada, para posterior reparcelamento do solo.

Foi previsto dentre as ferramentas de Ordenamento e Reestruturação Urbana, as quais destinam-se a promover alterações em áreas urbanas subutilizadas e com potencial de transformação, para atingir finalidades como dar maior aproveitamento à terra urbana, aumentar as densidades construtivas e demográficas, implantar novas atividades econômicas, gerar emprego e atender às necessidades de habitação e de equipamentos sociais para a população (conforme caput do artigo 134 da Lei 16050/2014).

Nos termos dos incisos do §2o do artigo 134 da Lei 16.050/2014, a utilização do Reordenamento Urbanístico Integrado depende da edição de lei específica, na qual deverão constar diversos condicionamentos ao uso dessa ferramenta, dentre os quais cabe destacar: i) necessidade de adesão mínima da população envolvida, inclusive proprietários, em relação ao projeto de reordenamento urbanístico; ii) elaboração de projeto urbanístico contemplando todos as medidas a serem executadas na intervenção, bem como os mecanismos de financiamento; iii) cálculo dos custos e benefícios do projeto, bem como a partilha equitativa dos mesmos entre os particulares envolvidos e o poder público; iv) previsão de contrapartida a ser exigida de forma proporcional de todos proprietários em razão dos benefícios gerados pela intervenção pública; v) ampla participação social, envolvendo elaboração, avaliação e controle de todo processo de implementação do projeto; vi) garantia de direito à moradia, no local de intervenção, para a população de baixa renda.

Esses condicionamentos estruturam um regime jurídico que aproxima o reordenamento urbanístico integrado da reparcelación del suelo, uma vez que contemplada a possibilidade de equidistribuição dos custos e benefícios do planejamento urbano, tal como ocorre no Direito Urbanístico Espanhol. A principal vantagem da equidistribuição dos custos e benefícios da 
urbanização, por sua vez, é superar a "loteria do planejamento urbano", descrita acima como uma das dificuldades que mais prejudicam a elaboração e a implementação dos planos urbanísticos.

Além disso, o regime jurídico do reordenamento urbanístico integrado no novo plano diretor de São Paulo (2014) o diferencia claramente da concessão urbanística ${ }^{14}$ prevista no anterior plano diretor de São Paulo, Lei no 13.430/2002 (revogada), cuja aplicação no chamado "Projeto Nova Luz" $^{15}$ gerou expressiva rejeição da opinião pública. Na legislação revogada, a Concessão Urbanística representava uma modalidade de execução de um plano urbanístico específico, pela qual o poder público poderia transferir a um particular todos os poderes necessários à execução do plano urbanístico, financiando a atuação da particular pela concessão da exploração econômica das áreas públicas e privadas resultantes da execução do projeto.

Novis (2011, p. 42) desenvolveu a seguinte concepção de concessão urbanística:

Em breves linhas, a concessão urbanística pressupõe que o ente privado realize todos os investimentos necessários em uma dada área pertencente ao cenário urbano, sem qualquer dispêndio de recursos públicos, e, em contrapartida, se remunere pela exploração, por sua conta e risco, dos terrenos e edificações destinados a usos privados resultantes das obras a serem realizadas, bem como da exploração de espaços públicos, de acordo com as disposições editalícias e contratuais aplicáveis à espécie.

A previsão da Concessão Urbanística no chamado Projeto Nova Luz provocou o receio de um forte processo de gentrificação. Além disso, também se previa o desmonte da economia instalada na região da Rua Santa Efigênia, mediante a substituição dos proprietários dos imóveis por grupos econômicos internacionais, os quais causariam uma sobrevalorização do solo e a especulação imobiliária ${ }^{16}$ daí decorrente. Nesse sentido, a concessão urbanística foi considerada como um mecanismo arbitrário de desapropriação e tredestinação de áreas públicas, uma vez que previa a transferência da propriedade, já incorporada ao domínio público, a particulares aliados aos interesses passageiros do governo da ocasião.

\footnotetext{
${ }^{14}$ Novis (2011), Dallari (2001) e Lomar (2001).

${ }^{15}$ Conforme Souza (2011).

${ }^{16}$ É provável que em razão desse histórico da concessão urbanística, o LabCidade (ligado à Faculdade de Arquitetura da USP), através do movimento pelo Direito à Cidade no Plano Diretor, tenha se oposto aos instrumentos de ordenamento e reestruturação urbana tal como elaborados inicialmente no projeto de lei original do atual Plano Diretor Estratégico de São Paulo, conforme se constata no sítio de internet "observaSP", encontrável no seguinte endereço eletrônico: https://observasp.wordpress.com/2014/07/28/sugestoes-de-emendas-ao-pl-68813-plano-diretor/
} 
O Reordenamento Urbanístico Integrado, portanto, representa uma tipologia diferenciada de instrumentos urbanísticos, uma vez que não se trata de simples instrumento de regulação para induzir o uso da propriedade, nem de mecanismo de transferência de poderes de autoridade pública na produção do espaço urbano para particulares contratados através de licitação. Vai além disso, configurando-se como uma competência privativa e inalienável do município, consistente em produzir o espaço urbano, instrumentalizando a propriedade privada para atendimento das finalidades públicas inscritas nos planos de reordenação do espaço urbano, os quais foram elaborados mediante ampla participação popular, garantindo-se uma apropriação pública e social do processo de urbanização.

Assim como a reparcelación del suelo, o Reordenamento Urbanístico Integrado funciona como um instrumento de execução dos planos urbanísticos, garantindo que a produção do espaço urbano seja publicamente apropriada, mediante processos de reordenação fundiária e equidistribuição dos custos e benefícios da produção do espaço urbano. A comparação entre os institutos, no entanto, demanda alguns esclarecimentos sobre o enquadramento legal e constitucional do Reordenamento Urbanístico Integrado no Direito Brasileiro, uma vez que não se pode transplantar um instituto jurídico de um ordenamento para outro. O objetivo do próximo item, portanto, será descrever esse enquadramento.

\section{O enquadramento jurídico do Reordenamento Urbanístico Integrado no Direito Urbanístico Brasileiro}

O Direito Urbanístico Brasileiro funda-se no princípio da função social da propriedade ${ }^{17}$, segundo o qual a propriedade deixa de ser um direito subjetivo ilimitado e passa a ter a natureza jurídica de um dever; o dever do detentor da riqueza de utilizá-la em função das finalidades preordenadas pela ordem jurídica.

Não é o caso de se aprofundar aqui a concepção de função social da propriedade, mas importa destacar a lição sempre atual de Silva (2000, p. 284-285), no sentido de que não se trata de simples limitação administrativa externa ao exercício do direito de propriedade, mas de verdadeira mutação na estrutura jurídica do direito de propriedade, que passa a ser um dever condicionado pela ordem jurídica, verdadeiro instituto de Direito Público.

\footnotetext{
17 Nesse sentido, ampla bibliografia pode ser apontada, destacando-se Mattos (2003; 2006), Fernandes (2006), Silva (2006), Pinto (2011), Rech (2010), Di Sarno (2004).
} 
Nesse contexto, o Município e o Plano Diretor ganharam uma importância fundamental na Constituição Federal de 1988. Conforme o §2ㅇ do artigo 182 da Constituição, a função social da propriedade será cumprida à medida em que as exigências de ordenação da cidade contidas no Plano Diretor forem obedecidas. Ocorre que o Plano Diretor é, dentre outros, um dos instrumentos da política de desenvolvimento urbano de que o município dispõe para atingir as funções sociais da cidade (cf. caput do art. 182 da Constituição Federal). Assim, o município deverá elaborar sua política de desenvolvimento urbano, necessariamente, articulando o Plano Diretor (conforme $\S 1$ ㅇ do artigo 182) a outros instrumentos de política urbana.

O Plano Diretor, portanto, será a faceta normativa dessa política de desenvolvimento urbano, que incluirá outros instrumentos de execução dos planos urbanísticos. A propriedade privada, portanto, não será condicionada apenas pelas diretrizes normativas do plano diretor, mas também por todos os outros instrumentos de política urbana que objetivem dar exequibilidade ao plano diretor. Dessa forma, existe uma base constitucional suficiente para autorizar o município a: (i) elaborar sua política de desenvolvimento urbano, mediante a edição do plano diretor e de outros instrumentos normativos e; (ii) aplicar os instrumentos normativos mediante instrumentos de execução que efetivamente condicionem a propriedade privada.

O Estatuto da Cidade, por sua vez, não enumerou de forma exauriente os instrumentos de política urbana, instituindo um quadro bastante abrangente para atuação dos municípios. Nesse sentido, o caput do art. 4ํ do Estatuto da Cidade é expresso ao admitir que os instrumentos de política urbana não se esgotam naqueles instrumentos expressamente definidos no Estatuto. E não poderia deixar de ser essa a solução, uma vez que se pretende preservar as competências municipais enquanto ente federativo com autonomia política e competência para definir a política urbana (artigo 182 da CF/88) e para executar o adequado ordenamento do território (artigo 30, inciso VIII, da CF/88).

Nesse contexto, é importante perceber o significado da regulação trazida pelo Capítulo II do Estatuto da Cidade. O referido Capítulo II é dividido em doze seções, voltadas a detalhar alguns instrumentos específicos de política urbana, à exceção da seção I, que trata "dos instrumentos em geral". Portanto, há onze seções que tratam de instrumentos específicos de política urbana e uma seção que regula de forma geral os instrumentos de política urbana, abrindo a possibilidade dos municípios criarem, mediante competência legislativa própria, outros instrumentos. Nesse contexto, é importante destacar que os instrumentos de política urbana detalhados no Capítulo II (artigos 5 a 38) são voltados à regulação do mercado 
imobiliário, desenhando uma função indutora para os municípios; não esgotam, dessa forma, as possibilidades de atuação dos municípios na execução de sua política urbana.

De fato, os municípios poderão criar novos instrumentos de política urbana no âmbito de sua competência legislativa em matéria de direito do urbanismo, conforme dispõe o artigo 30, incisos I e II, combinado com o artigo 182, caput, da Constituição Federal. Com isso, é possível compreender que o caráter exemplificativo dos instrumentos de política urbana do caput do artigo 4o do Estatuto da Cidade funciona como uma estratégia para reservar para a União o estabelecimento de normas gerais para aqueles instrumentos que digam respeito a competências da União, sem restringir indevidamente as competências próprias dos municípios.

A repartição constitucional de competências deve ser interpretada com clareza, de forma a nortear a aplicação dos dispositivos do Estatuto da Cidade. Nesse sentido, deve-se compreender que os instrumentos urbanísticos de indução e controle do mercado imobiliário são o direito de superfície, a desapropriação-sanção, a transferência do direito de construir e os outros institutos especificamente detalhados no Capítulo II do Estatuto da Cidade. Alguns desses institutos interferem na estrutura do direito de propriedade e estão relacionados a matérias de direito civil, constituindo competência privativa da União. Outros institutos compreendidos nesse conjunto, como a desapropriação-sanção ou o IPTU progressivo no tempo, referem-se a matérias que, ou são privativas da União (desapropriação), ou devem ser reguladas mediante normas gerais pela União (matéria tributária).

Dessa forma, dada a predominância de matérias de competência privativa da União, a regulamentação dos instrumentos de política urbana do Capítulo II do Estatuto da Cidade não poderia deixar de ser competência da União, assegurando-se aos municípios um amplo campo de atuação, na medida em que esses instrumentos não esgotam o conjunto das ferramentas de política urbana.

Essa sistemática de divisão de competências em relação aos instrumentos do Estatuto da Cidade é compatível com a ordem constitucional, uma vez que reserva para a lei federal a regulamentação detalhada dos instrumentos de indução do mercado imobiliário, abrindo a possibilidade para os municípios criarem outros instrumentos de política urbana, que não se configurem primariamente como instrumentos de indução e controle sobre o mercado imobiliário.

Nesse sentido, o Reordenamento Urbanístico Integrado pode ser enquadrado na hipótese do artigo 30, inciso VIII, da Constituição Federal, envolvendo não somente funções normativas de planejamento, mas também funções executórias de ordenação do território, as 
quais, em conjunto, convertem em realidade os planos urbanísticos. Nesse sentido, o Reordenamento Urbanístico Integrado deve ser considerado um novo instrumento urbanístico que incorpora uma nova função, a função urbanizadora, de produção e reprodução do espaço urbano, atribuída ao município nos termos do artigo 30, inciso VIII, da Constituição Federal.

O sentido dessa argumentação está em perceber que os artigos 30 e 182 da Constituição Federal não permitem mais interpretar que a produção e a reprodução do espaço urbano continuem a ser concebidas como funções decorrentes do direito de propriedade. A Constituição de 1988 definiu como públicos os processos de produção e reprodução do espaço urbano, criando uma nova função que aqui se designa como função urbanizadora, titulada exclusivamente pelo município (poder público e sociedade civil), para promover uma política de desenvolvimento urbano voltada à realização do direito fundamental à cidade.

Conforme se observa, o Reordenamento Urbanístico Integrado é um instrumento de execução dos planos urbanísticos, criado no âmbito da competência legislativa municipal, para institucionalizar a sua função de produzir o espaço urbano.

\section{CONCLUSÃO}

Mais de quinze anos depois da edição do Estatuto da Cidade, os espaços urbanos brasileiros permanecem caracterizados como espaços de exclusão e de grandes carências sociais e de serviços públicos para as populações que não podem custear com seus recursos melhores níveis de bem-estar.

Considerando-se a grande articulação social que levou à inclusão do Capítulo da Política Urbana na Constituição de 1988, a eficácia da regulamentação trazida pelo Estatuto da Cidade parece estar aquém das expectativas sociais que colocaram a reforma urbana como um ponto fundamental do pacto político de 1988.

A perspectiva em geral assumida é no sentido de que ainda é incompleta ou defectiva a aplicação dos instrumentos urbanísticos previstos no Estatuto da Cidade, havendo ainda muito esforço a ser desenvolvido para dar plena aplicabilidade aos instrumentos de política urbana na realização do direito fundamental à cidade.

A orientação defendida neste trabalho, no entanto, é no sentido de que o Estatuto da Cidade e os instrumentos de política urbana ainda são interpretados segundo uma perspectiva liberal que os reduz a mecanismos de regulação econômica, relegando ao mercado a primazia sobre processos de produção do espaço urbano. 
Essa orientação de se reduzir os instrumentos de política urbano a simples mecanismos de regulação econômica do mercado na produção do espação não é compatível com as diretrizes da política urbana na Constituição Federal de 1988, nem com as expectativas sociais que sustentaram o movimento de reforma urbana.

De forma coerente com essa conclusão, este trabalho defende a necessidade de publicização da produção do espaço urbano, através de uma releitura das competências constitucionais atribuídas ao município, de modo a enquadrar a função de produção do espaço urbano como um serviço público atribuído ao município.

Nesse sentido, o município tem a obrigação de que criar instrumentos de política urbana que possibilitem a produção do espaço urbano como execução de um serviço público municipal, tal como é o caso do Reordenamento Urbanístico Integrado, instituído no Plano Diretor de São Paulo de 2014.

De forma coerente com o princípio da função social da propriedade, este trabalho defende a tese de que a produção do espaço urbano não é uma atividade econômica privativa do mercado e regulada pelo Estado, abrindo assim um amplo campo de atuação e afirmação das coletividades locais como os verdadeiros detentores do poder de produzir a cidade.

\section{BIBLIOGRAFIA}

ARAUJO, Suely Mara Vaz Guimarães e LORENZETTI, Maria Silvia Barros (2008). “O parcelamento do solo e a responsabilidade territorial urbana". In: Cadernos ASLEGIS. № 34, pp. 13-38, maioagosto 2008.

BERCOVICI, Gilberto (2015). "O princípio da subsidiariedade e o autoritarismo." In: Revista Consultor Jurídico. Disponível em: BRASIL, Ministério das Cidades (2010). Regularização fundiária urbana: como aplicar a Lei Federal 11.977/2009. Brasília: Ministério das Cidades. 2010.

BRUM, Eliane (2017). “A Amazônia não é nossa". In: https://brasil.elpais.com/brasil/2017/10/02/opinion/1506961759 879609.html. Consultado em 02/10/2017. 
CARMONA, Paulo Afonso Cavichioli (2015). Curso de direito urbanístico. Salvador, Bahia: Editora Juspodium. 2015.

DALLARI, Adilson Abreu (2001). "Concessões urbanísticas". In: Ministério Público de São Paulo, Centro de Apoio das Promotorias de Justiça de Habitação e Urbanismo. Temas de direito urbanístico 3.

DI SARNO, Daniela Campos Libório (2004). Elementos de direito urbanístico. Barueri, SP: Manole. 2004.

FERNANDES, Edésio (2006). "A nova ordem jurídico-urbanística no Brasil". In: ALFONSIN, Betânia de Moraes e FERNANDES, Edésio (org.). Direito urbanístico, estudos brasileiros e internacionais. Belo Horizonte: Del 2006. http://www.conjur.com.br/2015-nov-08/estado-economia-principio-subsidiariedade-autoritaris mo?imprimir=1. Consultado em 02/05/2016.

LOMAR, Paulo José Villela (2001). A concessão urbanística. Tese de mestrado em direito urbanístico, defendida em 2001 na Pontifícia Universidade Católica de São Paulo.

MATTOS, Liana Portilho (2003). A efetividade da função social da propriedade urbana à luz do estatuto da cidade. Rio de Janeiro: Temas e Ideias editora. 2003.

MATTOS, Liana Portilho (2006). Nova ordem jurídico-urbanística, função social da propriedade na prática dos tribunais. Rio de Janeiro: Lumen Juris. 2006.

MONTANDON, Daniel Todtmann e SOUZA, Felipe Francisco de (2007). Land readjustment e operações urbanas consorciadas. São Paulo: Romano Guerra Editora. 2007.

MOREIRA, Egon Bockmann (2007). "O Direito Administrativo Contemporâneo e a Intervenção do Estado na Ordem Econômica." In: MARTINS, Humberto Falcão; MARINI, Caio; MODESTO, Paulo. Revista Eletrônica de Direito Administrativo Econômico. Salvador: Bahia. № 10 maio/junho/julho. 2007. Encontrável em: http://www.direitodoestado.com/revista/redae-10maio-2007-egon\%20boockman.pdf. 
NOVIS, Mariana (2011). O regime jurídico da concessão urbanística. Belo Horizonte: Fórum, 2011.

PINTO, Victor Carvalho (2010). "Do estatuto da cidade ao código de urbanismo." In: Senado Federal. Agenda legislativa para o desenvolvimento nacional - 2011. Encontrável em: https://www12.senado.leg.br/publicacoes/estudos-legislativos/outras-publicacoes\#temas-eagendas-para-o-desenvolvimento-sustentavel.

PINTO, Victor Carvalho (2011). Direito urbanístico: plano diretor e direito de propriedade. 3ạ edição. São Paulo: Revista dos Tribunais. 2011.

PINTO, Victor Carvalho (2013). Ebook Kindle. Função social da propriedade, origens doutrinárias de um conceito jurídico.

PINTO, Victor Carvalho (2013). O reparcelamento do solo: um modelo consorciado de renovação urbana. Brasília: Senado Federal - edição digital encontrável em https://www12.senado.leg.br/publicacoes/estudos-legislativos/tipos-de-estudos/textos-paradiscussao/td-130-reparcelamento-do-solo-urbano-um-modelo-consorciado-de-renovacaourbana.

RAMÓN, Fernando López (2013). Introducción al derecho urbanístico. Madrid: Marcial Pons. 2013.

RECH, Adir Ubaldo (2010). Direito urbanístico, fundamentos para construção de um plano diretor sustentável na área urbana e rural. Caxias do Sul: Educs. 2010.

ROLNIK, Raquel e KLINK, Jeroen (2011). "Crescimento econômico e desenvolvimento urbano. Por que nossas cidades continuam tão precárias?" In: CEBRAP. Novos Estudos. Março/2011, no 89, pp. 89-109.

SANTORO, Paula (org.) (2004). Gestão social da valorização da terra. São Paulo: Instituto Polis. Cadernos Polis, no 9. 2004. 
SAULE JÚNIOR, Nelson (2002). "Plano diretor - função social de propriedade". In: MATTOS, Liana Portilho. Estatuto da cidade comentado: lei n. 10.257, de 10 de julho de 2001. Belo Horizonte: Mandamentos. pp. 257-260. 2002.

SILVA, José Afonso da (2000). Curso de direito constitucional positivo. 18a edição. São Paulo: Malheiros. 2000.

SILVA, José Afonso da (2006). Direito urbanístico brasileiro. 4a edição. São Paulo: Malheiros. 2006.

SOUZA, Felipe Francisco (2011). A batalha pelo centro de São Paulo; Santa Ifigênia, concessão urbanística e projeto nova luz. São Paulo: Paulo's editora, 2011.

SOUZA, Felipe Francisco de (2009). Métodos de Planejamento Urbano: Projetos de Land Readjustment e Redesenvolvimento Urbano. São Paulo: Paulo's Comunicação, 2009.

TIMÓN, Antonio Jesus Alonso (2013). Introducción al derecho urbanístico. 2a edição. Valencia: Tirant lo Blanc. 2013.

Trabalho enviado em 13 de fevereiro de 2018.

Aceito em 07 de abril de 2018. 